Article

\title{
Monitoring and Management of Imidazolinone-Resistant Red Rice (Oryza sativa L., var. sylvatica) in Clearfield ${ }^{\circledR}$ Italian Paddy Rice
}

\author{
Laura Scarabel $^{1}$, Cesare Cenghialta ${ }^{2}$, Dario Manuello ${ }^{2}$ and Maurizio Sattin ${ }^{1, *}$ \\ 1 Institute of Agro-Environmental and Forest Biology-CNR, viale dell’Università 16, \\ 35020 Legnaro (PD), Italy; E-Mail: laura.scarabel@ibaf.cnr.it \\ 2 Rice Research Center-Ente Nazionale Risi, strada per Ceretto 4, 27030 Castello d'Agogna (PV), \\ Italy; E-Mails: c.cenghialta@enterisi.it (C.C.); d.manuello@enterisi.it (D.M.) \\ * Author to whom correspondence should be addressed; E-Mail: maurizio.sattin@ibaf.cnr.it; \\ Tel: +39-49-8272820; Fax: +39-49-8272839.
}

Received: 1 November 2012; in revised form: 10 December 2012 / Accepted: 12 December 2012 / Published: 19 December 2012

\begin{abstract}
The introduction in Italy of Clearfield $^{\circledR}$ rice cultivars carrying imidazolinone-resistant traits provides an efficient option to control red rice, a conspecific weed of cultivated rice. However, despite the promulgation of specific guidelines for Clearfield $^{\circledR}$ technology management, imazamox red rice survivors have been reported by farmers. Forty-two fields were monitored in 2010 and 2011 throughout the Piedmont and Lombardy regions and field cases were recorded of herbicides use and agronomic practices. Whole-plant sensitivity to imazamox was assessed and the resistance mechanism was determined by molecular analysis. Twenty-six red rice populations out of 42 were imazamox-resistant and plants of all the resistant populations possess a Ser to Asn substitution at locus 653 of the ALS gene determining the target-site resistance. Farmers frequently grow Clearfield ${ }^{\circledR}$ varieties for more than two consecutive years so increasing the selection pressure exerted by imazamox and favoring the evolution of resistant red rice. To maintain the sustainability of this new technology, a proper management based on crop rotation, utilization of certified seeds and strict control of red rice escapes has to be implemented. More generally, all stakeholders must increase their awareness that the selection pressure exerted by ALS inhibitors in rice cropping system should be reduced.
\end{abstract}


Keywords: weedy rice; Clearfield ${ }^{\circledR}$ rice cultivars; imazamox resistance; ALS inhibitors; IWM; point mutations; crop rotation

\section{Introduction}

Italy is the largest rice producer in Europe with an area of about 235,000 ha in 2012. The main rice cultivation area, about $90 \%$ of the total, is concentrated in the north-western regions of Piedmont and Lombardy where continuous paddy rice system is widespread. One of the key aspects of rice cultivation is the weed management because pedo-climatic conditions are favorable to weeds, there is a rich seed bank and weeds are generally competitive or very competitive. Consequently, farmers need to apply complex agronomic and chemical strategies to guarantee a good yield.

Red rice (Oryza sativa L., var. sylvatica) is one of the most troublesome weeds in Italian rice crops and it is also very difficult to control with common herbicides due to its botanical similarity to the cultivated rice. The infestations of red rice increased dramatically since 1990, likely because of the contamination of commercial seed lots as well as the introduction of semi-dwarf indica-type rice varieties, which are smaller, and therefore less competitive, than traditional Italian rice varieties [1]. This weed is now widespread in almost all rice growing areas and it is characterized by high seed shattering ability, long seed dormancy, and plants are taller and produce more tillers than cultivated rice. It also shows a wide variability of phenotypical, biological and physiological traits [2-4]. Most red rice grains have a red pigmented pericarp, although phenotypes with a white pericarp, which are similar to those of commercial rice varieties, have been reported [1]. The close similarity between red rice and the commercial rice varieties has prevented the application of post-emergence herbicides because of lack of selectivity. The best control programs are based on a combination of crop rotation as well as cultural and chemical practices [5-7]. False (or stale) seed bed preparation is the most common technique used by Italian rice farmers.

The introduction of imidazolinone-tolerant rice (IMI-rice), best known as Clearfield ${ }^{\circledR}$ varieties, has provided an efficient tool to selectively control red rice in post-emergence [8] and in Italy it is now cultivated on about 52,000 ha (i.e., more than one-fifth of total rice area), with new Clearfield ${ }^{\circledR}$ varieties appearing on the market. The IMI herbicide, i.e., an acetolactate synthase (ALS) inhibitor, allowed on Clearfield ${ }^{\circledR}$ varieties in Italy is imazamox. The Clearfield ${ }^{\circledR}$ rice cultivars have been developed through natural selection or induced mutation in the ALS gene, utilizing conventional plant breeding techniques [9]. Single nucleotide changes at codon 653 or 654 of the ALS gene (positions are referred to ALS from Arabidopsis thaliana), determining the substitution of serine with asparagine at codon 653 and the substitution of glycine with glutamic acid at codon 654, are responsible for imidazolinone resistance [9]. CL161 was the first Clearfield ${ }^{\circledR}$ rice variety marketed in Italy in 2006 having a mutation at codon 653 and named Libero. An IMI-R rice variety carrying a mutation at codon 122 (Ala to Thr substitution) of the ALS gene has been marketed in Argentina [10].

The major threat to the sustainability of the Clearfield ${ }^{\circledR}$ technology is that the IMI-tolerant trait might also be acquired by red rice through three possible mechanisms: (a) selection of spontaneous mutations conferring IMI resistance, or (b) cross-pollination between the Clearfield ${ }^{\circledR}$ variety and the 
wild relatives. Although some IMI-resistant mutants have been found in several weed species $[11,12]$ including red rice [13], the second mechanism (b) is considered to be more likely for rice/red rice, for which the crossing rates were estimated to be less than $1 \%$ [14], whereas the frequency of IMI resistance endowing spontaneous mutations is considered to be around $10^{-6}-10^{-8}[15,16]$. A third (c) "mechanism" can be related to the simple contamination of Clearfield ${ }^{\circledR}$ seed lots with IMI-resistant off-types originated and selected during the selection process of the variety and then favored by the positive selection pressure imposed by the IMI herbicide. The Italian law, which allows the presence of five red rice seeds in $500 \mathrm{~g}$ of commercial rice seed, makes this "mechanism" plausible.

The stewardship guidelines provided by BASF for the correct management of the Clearfield ${ }^{\circledR}$ technology suggest applying a double treatment of imazamox at the equal rate of $35 \mathrm{~g}$ a.i. ha ${ }^{-1}$, with the second treatment aimed at controlling red rice plants that might have escaped the first treatment and those that emerged later. Guidelines indicate that (a) Clearfield ${ }^{\circledR}$ rice should be rotated with conventional rice at least every two years of consecutive cultivation and (b) red rice plants that escaped the treatments should be totally removed. To preserve the Clearfield ${ }^{\circledR}$ technology, it is therefore vital to have complete control of the red rice infestation to avoid the consequent evolution of IMI-resistant red rice populations.

It should be noted that the introduction of the Clearfield ${ }^{\circledR}$ technology and its quick adoption by farmers is significantly increasing the already high reliance on ALS inhibitors for weed control in rice crops and therefore increasing the risk of selecting ALS resistant populations of other weed species [17], and especially Echinochloa spp. [18].

Unfortunately, a few years after the introduction of the Clearfield ${ }^{\circledR}$ technology in Italy, the first red rice survivors were reported by farmers. The aim of this work was to test for resistance large number of red rice seed samples collected after farmers' complaints about imazamox efficacy; to verify whether a target-site resistance mechanism is involved and identify possible mutation(s); to collect field histories of agronomic practices, especially weed control treatments of the sampled fields, relate them to the IMI-resistance status and to discuss the implications of the appearance of IMI-resistant red rice for the management guidelines (and weed management in rice).

\section{Results and Discussion}

\subsection{Field History of the Sampled Fields}

Red rice plants that escaped imazamox treatments were sampled in 42 fields across Piedmont and Lombardy regions (Table 1). The largest number of samples (25) was collected in the province of Pavia (PV), in Lombardy. Although it was not possible to obtain complete information about field treatments and practices from all farmers, the data collected show that the rotation of Clearfield ${ }^{\circledR}$ with conventional rice was implemented in 10 fields. Clearfield ${ }^{\circledR}$ rice was cultivated for at least 4 consecutive years in 11 fields, with 7 where continuous IMI-tolerant varieties were grown for at least 5 out of 6 years since 2006 and three where Clearfield ${ }^{\circledR}$ varieties had been cultivated continuously for six years. The latter fields therefore received 12 IMI treatments in 6 years. It seems clear that several farmers did not carefully follow the guidelines for cultivation provided by BASF that are attached to the contract they have to sign with this company in order to be able to cultivate Clearfield ${ }^{\circledR}$ rice. 
Table 1. Origin of red rice populations tested, resistance status and amino acid change at codon 653 of the acetolactate synthase (ALS) gene. Province: $\mathrm{PV}=$ Pavia, $\mathrm{MI}=$ Milan, $\mathrm{BI}=$ Biella, $\mathrm{VC}=$ Vercelli, $\mathrm{NO}=$ Novara, $\mathrm{AL}=$ Alessandria. Phenotype: $\mathrm{S}=$ imazamox susceptible, $\mathrm{R}=$ imazamox resistant.

\begin{tabular}{|c|c|c|c|c|c|c|c|}
\hline IBAF Code & Sampling Year & Location (province) & No. IMI treatments $(*)$ & Rotation & $\begin{array}{c}\text { Cyperaceae and } \\
\text { Echinochloa not controlled }\end{array}$ & Phenotype & Amino acid \\
\hline $010-1$ & 2010 & Ottobiano (PV) & None & No & No & $\mathrm{S}$ & Ser \\
\hline $010-2$ & 2010 & Torre d'Isola (PV) & None & No & No & $\mathrm{S}$ & Ser \\
\hline 010-3 & 2010 & Cergnago (PV) & None & No & No & $\mathrm{S}$ & - \\
\hline $010-4$ & 2010 & Rosate (MI) & $4-(2)$ & No & No & $\mathrm{S}$ & - \\
\hline $010-5$ & 2010 & Salussola (BI) & $2-(1)$ & No & No & $\mathrm{R}$ & Ser/Asn \\
\hline $010-6$ & 2010 & Zerbolò (PV) & $2-(1)$ & No & No & $\mathrm{R}$ & Asn \\
\hline $010-7$ & 2010 & Santhià (VC) & $6-(3)$ & No & No & $\mathrm{S}$ & - \\
\hline $010-8$ & 2010 & Robbio (PV) & $2-(1)$ & No & No & $\mathrm{S}$ & - \\
\hline $010-9$ & 2010 & Borgo Lavezzaro (NO) & $2-(1)$ & No & No & $\mathrm{R}$ & Ser/Asn \\
\hline 010-10 & 2010 & Bianzè (VC) & $8-(4)$ & No & No & $\mathrm{S}$ & - \\
\hline 010-11 & 2010 & Ottobiano (PV) & $6-(3)$ & No & No & $\mathrm{R}$ & Asn \\
\hline 010-12 & 2010 & Lomello (PV) & $10-(5)$ & No & No & $\mathrm{R}$ & Asn \\
\hline 010-13 & 2010 & Sannazzaro de Burgondi (PV) & $6-(3)$ & No & No & $\mathrm{R}$ & Ser/Asn \\
\hline 010-14 & 2010 & Ferrera Erbognone (PV) & $10-(5)$ & No & No & $\mathrm{R}$ & Asn \\
\hline 010-15 & 2010 & Pomaro Monferrato (AL) & $6-(3)$ & No & No & $\mathrm{S}$ & - \\
\hline 010-17 & 2010 & Castelnovetto (PV) & $2-(1)$ & No & No & $\mathrm{R}$ & Asn \\
\hline 010-18 & 2010 & Pomaro Monferrato (AL) & $8-(4)$ & No & No & $\mathrm{S}$ & - \\
\hline 011-19 & 2011 & Ferrera Erbognone (PV) & $8-(4)$ & No & No & $\mathrm{R}$ & Asn \\
\hline 011-20 & 2011 & Olevano Lomellina (PV) & $2-(1)$ & No & No & $\mathrm{R}$ & Asn \\
\hline $011-21$ & 2011 & Ceretto Lomellina (PV) & $10-(5)$ & No & No & $\mathrm{R}$ & Asn \\
\hline $011-22$ & 2011 & Castello d'Agogna (PV) & $4-(5)$ & Yes & No & $\mathrm{S}$ & - \\
\hline $011-23$ & 2011 & Sannazzaro de Burgondi (PV) & $6-(3)$ & No & No & $\mathrm{R}$ & Asn \\
\hline $011-24$ & 2011 & Bianzè (VC) & $4-(5)$ & Yes & No & $\mathrm{S}$ & Ser \\
\hline
\end{tabular}


Table 1. Cont.

\begin{tabular}{|c|c|c|c|c|c|c|c|}
\hline IBAF Code & Sampling Year & Location (province) & No. IMI treatments (*) & Rotation & $\begin{array}{c}\text { Cyperaceae Echinochloa not } \\
\text { controlled }\end{array}$ & Phenotype & Amino acid \\
\hline $011-25$ & 2011 & Vespolate (NO) & $2-(3)$ & Yes & No & $\mathrm{R}$ & Asn \\
\hline $011-26$ & 2011 & Santhià (VC) & $6-(3)$ & No & No & $\mathrm{R}$ & Asn \\
\hline 011-27 & 2011 & Vercelli (VC) & $4-(3)$ & Yes & Yes & $\mathrm{R}$ & Asn \\
\hline $011-28$ & 2011 & Garbagna Novarese (NO) & $4-(4)$ & Yes & No & $\mathrm{S}$ & - \\
\hline $011-29$ & 2011 & Langosco (PV) & $6-(3)$ & No & No & $\mathrm{S}$ & - \\
\hline 011-30 & 2011 & Robbio (PV) & $2-(2)$ & Yes & Yes & $\mathrm{S}$ & - \\
\hline 011-31 & 2011 & Livorno Ferraris (VC) & $6-(3)$ & No & No & $\mathrm{S}$ & - \\
\hline 011-32 & 2011 & Lomello (PV) & $12-(6)$ & No & No & $\mathrm{R}$ & Asn \\
\hline 011-33 & 2011 & Ottobiano (PV) & $12-(6)$ & No & No & $\mathrm{R}$ & Asn \\
\hline 011-34 & 2011 & Ferrera Erbognone (PV) & $10-(6)$ & No & No & $\mathrm{R}$ & Asn \\
\hline $011-35$ & 2011 & Sannazzaro de Burgondi (PV) & $8-(6)$ & No & No & $\mathrm{R}$ & Asn \\
\hline $011-36$ & 2011 & Pieve del Cairo (PV) & $12-(6)$ & No & No & $\mathrm{R}$ & Asn \\
\hline $011-37$ & 2011 & Gambarana (PV) & $4-(6)$ & Yes & No & $\mathrm{S}$ & - \\
\hline 011-38 & 2011 & Olevano Lomellina (PV) & $8-(6)$ & Yes & No & $\mathrm{R}$ & Asn \\
\hline 011-39 & 2011 & San Giorgio Lomellina (PV) & $6-(6)$ & No & No & $\mathrm{S}$ & - \\
\hline $011-40$ & 2011 & Semiana (PV) & $4-(2)$ & No & Yes & $\mathrm{R}$ & Asn \\
\hline $011-41$ & 2011 & Zeccone (PV) & $4-(2)$ & No & Yes & $\mathrm{R}$ & Asn \\
\hline $011-42$ & 2011 & Noviglio (MI) & $6-(3)$ & No & Yes & $\mathrm{R}$ & Asn \\
\hline 011-43 & 2011 & Noviglio (MI) & $6-(3)$ & No & Yes & $\mathrm{S}$ & - \\
\hline $011-44$ & 2011 & Vernate (MI) & $4-(3)$ & Yes & Yes & $\mathrm{S}$ & - \\
\hline $011-45$ & 2011 & Ottobiano (PV) & $6-(3)$ & No & No & $\mathrm{R}$ & Asn \\
\hline $011-46$ & 2011 & Pomaro Monferrato (AL) & $6-(6)$ & Yes & No & $\mathrm{R}$ & Asn \\
\hline
\end{tabular}

$\left(^{*}\right)$ Two IMI treatments are recommended in the guidelines for Clearfield ${ }^{\mathbb{R}}$ varieties cultivation. In brackets the no. of years for which field records were available. 
In fact, the guidelines recommend that Clearfield ${ }^{\circledR}$ varieties should not be grown in the same field for more than two consecutive years. Although the situation is rather different, it is worth pointing out that the guidelines used in USA recommend rotating Clearfield ${ }^{\circledR}$ rice annually with other crops [19]. However, the field histories also prove that virtually all farmers follow the guidelines in relation to the no. of imazamox treatments per year (i.e., two).

In addition, difficulties in controlling Echinochloa spp. and sedges have been reported for seven of the sampled fields (Table 1). The cultivation of Clearfield ${ }^{\circledR}$ rice is a valuable tool for controlling red rice, but this technology has to be seen in the context of the rice cropping system as a whole, where there is already an intense use of ALS inhibitors. More than $90 \%$ of Italian rice fields are treated at least once per year with this group of herbicides and ALS-resistant populations of four other weed species is widespread [17,20]. The selection pressure imposed by the repeated use of imazamox therefore determines an increased risk of resistance evolution in rice weeds, especially in Echinochloa spp. [18].

\subsection{Whole-Plant Resistance Assessment}

The first screening was conducted on 17 red rice populations collected in 2010. The three susceptible checks (010-1, 010-2 and 010-3) were totally controlled by imazamox at the recommended field dose $(1 \times$, Figure 1). Among the suspected resistant populations, eight were highly resistant to imazamox, with plant survival ranging between 48 and $98 \%$ at dose $1 \times$ (Figure 1). The biomass of these surviving plants was always high and ranged between 73 and $98 \%$ of the untreated control, indicating that the plants were scarcely affected by the herbicide. In population $010-8$ only a few plants were imazamox-resistant but they were badly affected by the treatment, as shown by the VEB value of $48 \%$. The remaining five populations were still susceptible.

Figure 1. First screening: plant survival (blue bars) and visual estimation biomass (VEB, white bars) for each tested population of red rice treated with imazamox at dose $1 \times$ ( $35 \mathrm{~g}$ a.i. $\mathrm{ha}^{-1}$ ). Standard error is reported for each bar. The first three populations on the left are the susceptible ones.

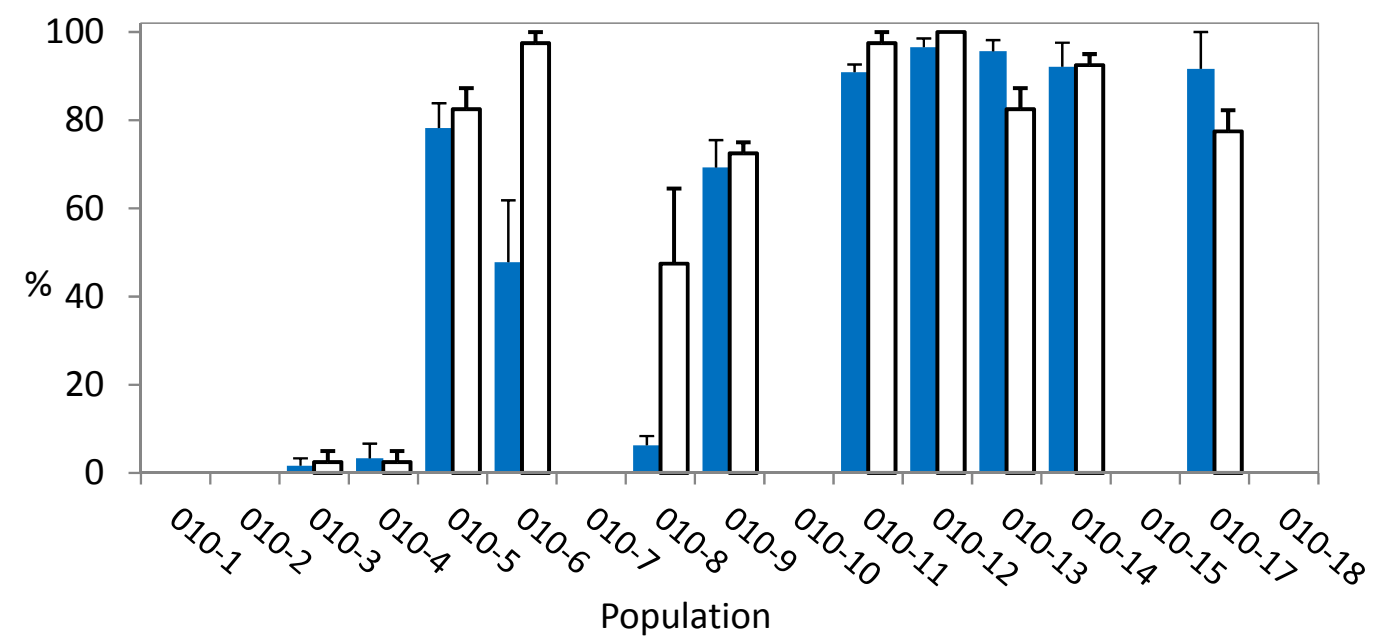


In the second screening all resistant populations were retested at two doses of imazamox, $1 \times$ and $3 \times$. ANOVA showed that the plant survival did not significantly differ between imazamox doses $(F=0.057 ; P=0.82)$. Moreover, plant survival of all the populations treated at dose $1 \times$ was similar to that observed in the first screening, with plant survival varying between 52 and $100 \%$ and 74 and $93 \%$ at dose $1 \times$ and $3 \times$, respectively (data not shown).

The third screening tested the response to imazamox at dose $1 \times$ of the 28 red rice populations collected in 2011 and showed that 18 populations were highly resistant to imazamox at the recommended field dose, with plant survival ranging between 78 and 100\% (Figure 2). Only population 011-42 showed a lower value of 35\%. Instead, all the survived plants had a high VEB, always above $85 \%$ indicating that they were not affected by the herbicide. In population 011-44 only 2 plants survived and their biomass was similar to that of the untreated control.

Figure 2. Third screening: plant survival (blue bars) and visual estimation biomass (VEB, white bars) for each tested population of red rice treated with imazamox at dose $1 \times$ ( $35 \mathrm{~g}$ a.i. $\mathrm{ha}^{-1}$ ). Standard error is reported for each bar. The first population on the left is the susceptible one.

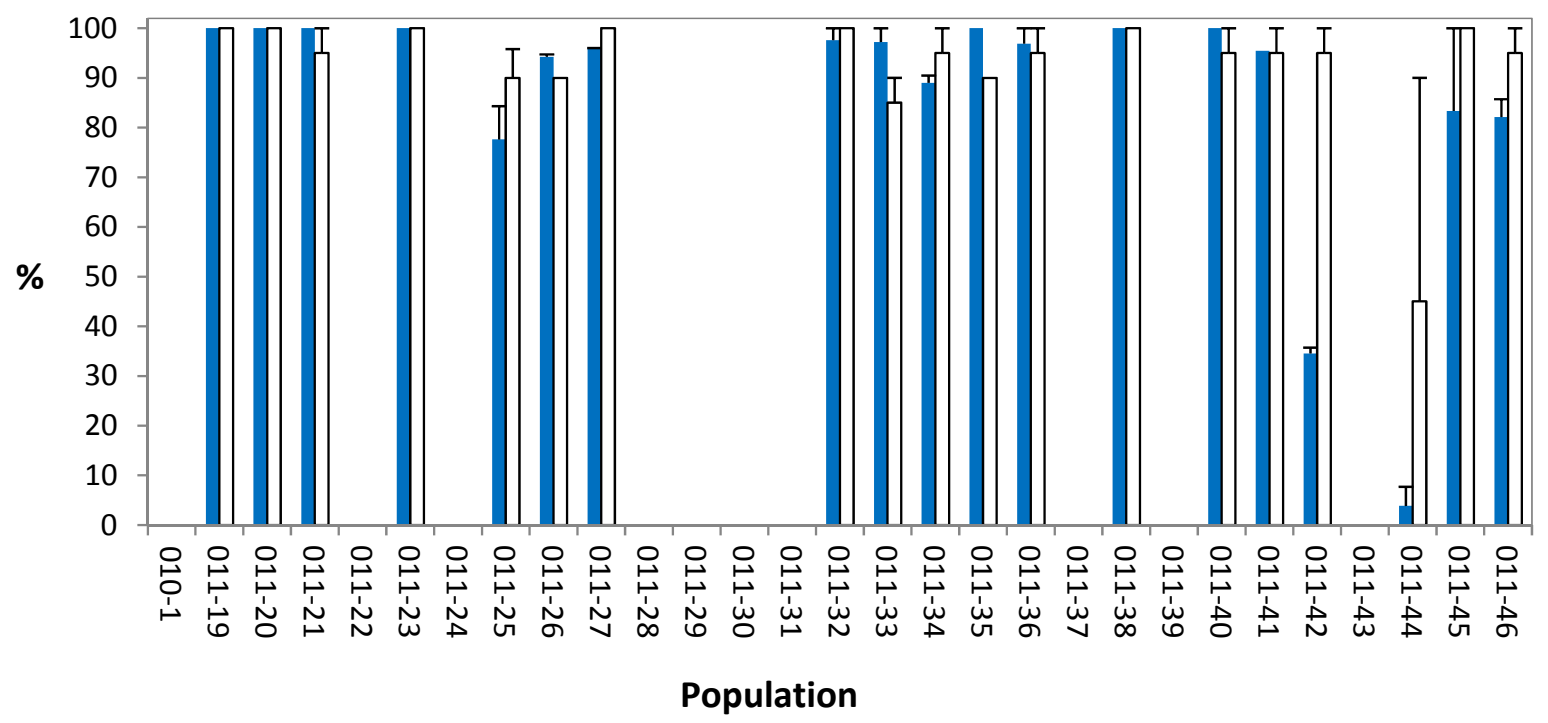

The confirmation of 26 imazamox-resistant red rice populations indicates that resistance is already present in all major rice producing Italian provinces and that it is significantly more diffused than reported by Busconi et al. [19], where resistant red rice was found in six locations of one province of the Piedmont region.

\subsection{Resistance Mechanism}

Genomic DNA was extracted from plants of the 26 resistant populations and from three susceptible populations: $010-1,010-2$ and 011-24. The combination of specific primers ORY-2F/ORY-2R amplified a fragment of the expected size at the 3 'end of the ALS gene. The alignment of the nucleotide sequences of the ALS-amplified region of the resistant and susceptible plants showed only 
one nucleotide substitution at position 653 (position referred to Arabidopsis thaliana (L.) Heynh. ALS sequence). In the susceptible populations, all plants had a AGT encoding a serine, while in all the resistant populations analyzed, plants had an AAT encoding an asparagine (Table 1). The mutation found in the ALS gene is the same as that present in the IMI-R rice cultivar, Libero, commercialized in Italy since 2006 [19].

Most of the resistant plants analyzed were homozygous at codon 653. Only plants of populations 010-5, 010-9 and 010-13 were heterozygous at this locus (Table 1). The presence of homozygous genotypes proves that the hybridization process resulting in transfer of the herbicide resistance trait to red rice occurred at least two years before seed sampling. It is therefore conceivable that the hybridization events took place in the early years of the introduction of the Clearfield ${ }^{\circledR}$ rice variety Libero. The progenies were then able to multiply following the selection pressure exerted by the continuous use of imazamox. Instead, the presence of heterozygous plants at the ALS locus may be the result of a hybridization event during the sampling year or due to the segregation of the F2 generation [19].

The fact that homozygous plants were found in population 011-25 after one year of Clearfield ${ }^{\circledR}$ cultivation (see Table 1) suggests that there may have been a contamination of the commercial seed batch used for sowing. This hypothesis is plausible because five seeds of red rice in $500 \mathrm{~g}$ of rice is permissible in Italy. An analogous case has been hypothesized in Brazil where imidazolinone resistant weedy rice was reported after the first year of IMI-R rice planting [10].

A morphological observation of the red rice seeds revealed that some of the populations tested had both red as well as a few white and intermediate colored seeds. This may imply that some of the resistant plants, i.e., those originating from white seeds, belong to off-types originating during the selection process of the Clearfield ${ }^{\circledR}$ variety. Therefore, although gene flow is likely to be the main origin of the IMI-resistant red rice [21,22], further studies are needed to fully clarify the origin of the red rice mutants.

\subsection{Sustainable Weed Management for Clearfield ${ }^{\circledR}$ Technology}

In the next years new IMI-tolerant rice cultivars will be ready for commercialization (10 will be available for the next cropping season) and so it is likely that the area cultivated with Clearfield ${ }^{\circledR}$ varieties will increase further. To maintain the Clearfield ${ }^{\circledR}$ technology alive, farmers should strictly follow the guidelines provided by BASF at time of seed purchase. Firstly, only certified seed batches should be used and imazamox should be sprayed at the rate and timings reported on the label; and secondly the cultivation of IMI tolerant varieties for more than two consecutive years must be avoided. Actually, considering the rapid diffusion of IMI-resistant red rice demonstrated in this study, it would appear reasonable to carefully re-evaluate the guidelines and recommend rotating Clearfield ${ }^{\circledR}$ varieties $^{-}$ annually with traditional rice varieties or other crops. In the case of escaped red rice plants, farmers must remove them at any cost before seeds shattering and report to BASF and/or the advisory service of the Ente Nazionale Risi.

Clearfield $^{\circledR}$ technology should be integrated into a complex weed management strategy that includes the use of all available tools and techniques. Stale seed-bed preparation allows the germination of red rice seeds and the subsequent control of seedlings with a burn-down herbicide 
before sowing. Soil tillage should be avoided after the harvest, leaving red rice seeds to decompose over the winter or be predated by birds [23]. If the field is tilled, the red rice seeds will be buried and become deeply dormant. Rotation of rice with other crops, such as soybean or maize, and winter flooding can also be used to reduce the red rice seed-bank [24].

Although the best strategy to preserve the Clearfield ${ }^{\circledR}$ technology is prevention, in the presence of IMI-resistant red rice more specific measures must be implemented. In addition to manual weeding, it is necessary to stop the cultivation of Clearfield ${ }^{\circledR}$ rice varieties and go for traditional varieties with a short growing cycle that allows to delay the sowing after the second half of May as well as preserving a good yield. In case of heavy infestation of resistant red rice, the only solution is to rotate rice with other crops where herbicides having a different mode of action can be used. This would also be useful for controlling others ALS-resistant weeds which might be present in the same field.

The herbicide resistance issue in rice crops needs a wider and more integrated management approach because the sustainability of the entire Italian rice cropping system is threatened by the very high selection pressure exerted by the intense use of ALS-inhibiting herbicides in time and space and consequent fast selection of resistant populations belonging to various weed species $[17,18,20]$. The high biological activity and good ecotoxicological and environmental profile of these herbicides, as well as the lack of new modes of action in the near future, impel stakeholders to preserve their efficacy for as long as possible.

\section{Experimental Section}

\subsection{Plant Material}

Seeds of 42 populations of red rice that had escaped the treatments with imazamox in Clearfield ${ }^{\circledR}$ rice fields of the north-western Italy were collected in 2010 and 2011. Seeds from three susceptible populations (010-1, 010-2 and 010-3) that had never been treated with IMI-inhibitors were also collected in the same region. Each seed sample was collected from at least 20 plants of red rice, based on morphological traits. Seed samples were then cleaned and stored at room temperature. Every effort was made to collect from farmers as much information as possible on agronomic practices, and especially herbicide use, of sampled fields starting from the introduction of the Clearfield ${ }^{\circledR}$ varieties in 2006. The complete list of red rice populations used in the experiments is reported in Table 1.

\subsection{Whole-Plant Imazamox Sensitivity Assessment}

Seeds of red rice were directly sown in plastic boxes $(24 \mathrm{~cm} \times 30 \mathrm{~cm} \times 9 \mathrm{~cm})$ filled with a substrate containing $60 \%$ silty loam soil, $15 \%$ sand, $15 \%$ perlite and $10 \%$ peat by volume and placed in a greenhouse at Legnaro, north-eastern Italy $\left(45^{\circ} 21^{\prime} \mathrm{N}, 11^{\circ} 58^{\prime} \mathrm{E}\right)$. Experiments were carried out during February-May period and plants were light supplemented using $400 \mathrm{~W}$ metal-halide lamps, which provided a Photosynthetic Photon Flux Density (PPFD) of about $400 \mu \mathrm{mol} \mathrm{m} \mathrm{m}^{-2} \mathrm{~s}^{-1}$ and a 16-hour photoperiod. Minimum temperatures ranged between 14 and $19{ }^{\circ} \mathrm{C}$ while maximum temperatures varied between 22 and $34^{\circ} \mathrm{C}$. About twenty days after sowing, seedlings were thinned to 20 plants per box and then plants were treated at the four-leaf stage. The experimental layout was a complete 
randomised design with two replicates. An untreated control per each population was always included. This protocol was followed in the three experiments performed.

In the first, 14 suspected resistant and 3 susceptible populations collected in 2010 were treated with the recommended field dose $(1 \times)$ of imazamox (Altorex, BASF, $40 \mathrm{~g}$ a.i. $\mathrm{L}^{-1}$, solution) at $35 \mathrm{~g}$ a.i. $\mathrm{ha}^{-1}$. The second experiment repeated the first one with the addition of the treatment at three times the recommended field dose $(3 \times)$. The third experiment was conducted on the 28 red rice populations collected in 2011 and the imazamox treatment was done at the recommended field dose $(1 \times)$.

The herbicide was distributed by using a precision bench sprayer delivering $300 \mathrm{~L} \mathrm{ha}^{-1}$ at a pressure of $215 \mathrm{kPa}$ and speed of about $0.75 \mathrm{~m} \mathrm{~s}^{-1}$, with a boom equipped with three flat-fan (extended range) hydraulic nozzles (Teejet $\left.{ }^{\circledR}, 11002\right)$. Plants were watered daily as required.

Four weeks after herbicide treatment, the number of surviving plants and a visual estimation biomass, giving a score of 10 to the untreated check and 0 to replicates where all plants were dead, were recorded. Plants were assessed as being dead if, regardless of color, they showed no active growth. Standard error (SE) was calculated for each mean. Populations were ascribed to be resistant when more than $20 \%$ of plants survived the $1 \times$ dose.

An ANOVA (significance level $P<0.05$ ) was performed to analyze the effect of the imazamox dose on plant survival. The statistical analysis was done by using the software Statistica 6.1 (StatSoft, Tulsa, USA; http://www.statsoft.com [25]).

\subsection{DNA Extraction and Amplification}

Leaf samples for DNA extraction were done on individual plants of red rice before imazamox treatment. In this way it was possible to analyze the ALS sequence for both resistant and susceptible plants. Genomic DNA was extracted from plants of all the populations reported in Table 1 using the CTAB method [26]. All extractions were performed using $0.1 \mathrm{~g}$ of fresh leaves. Specific primers were designed on regions of high homology among the ALS gene sequence available in Genebank: Oryza sativa (Japonica cultivar-group) AY885674.1. The primer combination ORY-2F (5'-CAGGAGTT GGCATTGATCCGC-3')/ORY-2R (5'-ACACAGTCCTGCCATCACCATC-3') amplified a genomic fragment of $372 \mathrm{bp}$ at the $3^{\prime}$ of the ALS gene. PCR reactions was conducted using the Advantage ${ }^{\circledR}$ 2 PCR Kit (Clontech) in a $50 \mu \mathrm{L}$ mixture of $1 \times$ Advantage $^{\circledR} 2$ SA buffer, $0.2 \mu \mathrm{M}$ of each primer, $0.2 \mathrm{mM}$ of each dNTP, $1 \mu \mathrm{L}$ of proofreading Advantage 2 Polymerase mix and $100 \mathrm{ng}$ of genomic DNA template. The following PCR program was done: $1 \mathrm{~min}$ at $95{ }^{\circ} \mathrm{C}$, then 30 cycles of $30 \mathrm{~s}$ at $95^{\circ} \mathrm{C}$, $30 \mathrm{~s}$ at $60^{\circ} \mathrm{C}$ and $40 \mathrm{~s}$ at $68{ }^{\circ} \mathrm{C}$. Final extension time was $3 \mathrm{~min}$ at $68^{\circ} \mathrm{C}$. PCR products were extracted from $1 \%$ agarose gel stained with $\mathrm{SYBR}^{\circledR}$ Safe DNA gel stain (Invitrogen) and purified using MinElute Gel Extraction Kit (Qiagen) following the manufacturer's instructions. Sequencing was carried out by an ABI 3730XL sequencer (Applied Biosystems). Sequence analysis and alignments were performed using the BioEdit software [27]. 


\section{Conclusions}

Through a large survey based on complaint monitoring, twenty six populations of red rice from fields of Clearfield ${ }^{\circledR}$ rice varieties were confirmed to be highly resistant to imazamox. These cases affect all main provinces where rice is grown in Italy. This means that since the first resistance cases reported in 2010 in just one province, imidazolinone-resistant red rice has been spreading rapidly and so threatening the sustainability of the Clearfield ${ }^{\circledR}$ technology. All imazamox-resistant plants possessed a nucleotide substitution at position 653 and most of them were homozygous at this codon. Farmers have quickly adopted the IMI-tolerant rice varieties to efficiently control red rice but have not been so diligent in following the guidelines provided by the company. Without a proper management based on frequent crop rotation, utilization of certified seeds and strict control of red rice escapes, this new technology appears not to be sustainable. More generally, all stakeholders must increase their awareness that the selection pressure exerted by ALS inhibitors in the rice cropping system should be reduced.

\section{Acknowledgments}

The research was jointly supported by the Italian National Research Council (CNR) and Ente Nazionale Risi. The authors are grateful to some of the members of the Italian herbicide resistance working group (GIRE) for providing the seed samples, to Valentina Rosan for helping with molecular analysis and to Alison Garside for revising the English.

\section{References}

1. Ferrero, A.; Vidotto, F.; Balsari, P.; Airoldi, G. Mechanical and chemical control of red rice (Oryza sativa L. var. sylvatica) in rice (Oryza sativa L.) pre planting. Crop Prot. 1999, 18, 245-251.

2. Craigmiles, J.P. Introduction. In Red Rice: Research and Control; Easting, E.F., Ed.; Texas Agri. Exp. Stn. Bull; Texas A\&M University: College Station, TX, USA, 1978; pp. 5-6.

3. Kwon, S.L.; Smith, R.J.; Talbert, R.E. Comparative growth and development of red rice (Oryza sativa) and rice (O. sativa). Weed Sci. 1992, 40, 57-62.

4. Fogliatto, S.; Vidotto, F.; Ferrero, A. Morphological characterisation of Italian weedy rice (Oryza sativa) populations. Weed Res. 2012, 52, 60-69.

5. Parker, C.; Dean, M.L. Control of wild rice in rice. Pestic. Sci. 1976, 7, 403-416.

6. Català Forner, M. Chemical and cultural practices for red rice control in rice fields in Ebro Delta (Spain). Crop Prot. 1995, 14, 405-408.

7. Ferrero, A.; Vidotto, F. Shattering ability of red rice seeds in cultural conditions. In Proceedings of the 50th International Symposium on Crop Protaction, Gent, Belgium, 5 May 1998; Volume 50, pp. 839-843.

8. Webster, E.P.; Masson, J.A. Acetolactate synthase-inhibiting herbicides on imidazolinone-tolerant rice. Weed Sci. 2001, 49, 652-657.

9. Tan, S.; Evans, R.R.; Dahmer, M.L.; Singh, B.K.; Shaner, D.L. Imidazolinone-tolerant crops: History, current status and future. Pest Manag. Sci. 2005, 61, 246-257. 
10. Gressel, J.; Valverde, B.E. A strategy to provide long-term control of weedy rice while mitigating herbicide resistance transgene flow, and its potential use for other crops with related weeds. Pest Manag. Sci. 2009, 65, 723-731.

11. Tranel, P.J.; Wright, T.R. Resistance of weeds to ALS-inhibiting herbicides: What have we learned? Weed Sci. 2002, 50, 700-712.

12. Tranel, P.J.; Wright, T.R.; Heap, I.N. ALS mutations from resistant weeds. Available online: http://www.weedscience.org (accessed on 20 October 2012).

13. Sales, M.A.; Shivrain, V.K.; Burgos, N.R.; Kuk, Y.I. Amino acid substitutions in the acetolactate synthase gene of red rice (Oryza sativa) confer resistance to imazethapyr. Weed Sci. 2008, 56, 485-489.

14. Gealy, D.R.; Mitten, D.H.; Rutger, J.N. Gene flow between red rice (Oryza sativa) and Herbicide-resistant rice (O. sativa): implications for weed management. Weed Technol. 2003, 17, 627-645.

15. Chaleff, R.S.; Day, E.B. Herbicide resistant mutants from tabacco cell cultures. Science 1984, 223, 1148-1151.

16. Olofsdotter, M.; Valverde, B.E.; Madsen, K.H. Herbicide resistant rice (Oryza sativa L.): Global implications for weedy rice and weed management. Ann. Appl. Biol. 2000, 137, 279-295.

17. Scarabel, L.; Locascio, A.; Furini, A.; Sattin, M.; Varotto, S. Characterisation of ALS genes in the polyploid species Schoenoplectus mucronatus and implications for resistance management. Pest Manag. Sci. 2009, 66, 337-344.

18. Panozzo, S.; Scarabel, L.; Tranel, P.J.; Sattin, M. Target-site resistance to ALS inhibitors in the polyploid species Echinochloa crus-galli . Pestic. Biochem. Phys. 2012, submitted.

19. Busconi, M.; Rossi, D.; Lorenzoni, C.; Baldi, G.; Fogher, C. Spread of herbicide-resistant weedy rice (red rice, Oryza sativa L.) after 5 years of Clearfield rice cultivation in Italy. Plant Biol. 2012, 14, 751-759.

20. Sattin, M.; Berto, D.; Zanin, G.; Tabacchi, M. Resistance to ALS inhibitors in weeds of rice in north-western Italy. In Proceedings of International Brighton Conference on Weeds, Brighton, UK, 15-18 November 1999; Marshal, G., Ed.; British Crop Protection Council: Surrey, UK, 1999; Volume 1-3, pp. 783-790.

21. Gealy, D.R. Gene movement between rice (Oryza sativa) and weedy rice (Oryza sativa) —A US temperate rice perspective. In Crop Ferality and Volunteerism; Gressel, J., Ed.; CRC Press Taylor and Francis Group: Boca Raton, FL, USA, 2005; pp. 323-354.

22. Shivrain, V.K.; Burgos, N.R.; Anders, M.M.; Rajguru, S.N.; Moore, J.; Sales, M.A. Gene flow between Clearfield ${ }^{\mathrm{TM}}$ rice and red rice. Crop Prot. 2007, 26, 349-356.

23. Fogliatto, S.; Vidotto, F.; Ferrero, A. Germination of weedy rice in response to field conditions during winter. Weed Technol. 2011, 25, 252-261.

24. Fogliatto, S.; Vidotto, F.; Ferrero, A. Effects of winter flooding on weedy rice (Oryza sativa L.). Crop Prot. 2010, 29, 1232-1240.

25. Software Statistica 6.1; StatSoft: Tulsa, OK, USA, 2004. Available online: http://www.statsoft.com (accessed on 25 September 2012).

26. Doyle, J.; Doyle, J.L. A rapid DNA isolation procedure for small quantities of fresh leaf tissue. Phytochem. Bull. 1987, 19, 11-15. 
27. Hall, T.A. BioEdit: A user-friendly biological sequence alignment editor and analysis program for Windows 95/98/NT. Nucleic Acids Symp. Ser. 1999, 41, 95-98.

(C) 2012 by the authors; licensee MDPI, Basel, Switzerland. This article is an open access article distributed under the terms and conditions of the Creative Commons Attribution license (http://creativecommons.org/licenses/by/3.0/). 